\title{
Factors influencing the body temperature of 3-4 month old infants at home during the day
}

\author{
E S Anderson, S A Petersen, M P Wailoo
}

\begin{abstract}
Continuous recordings of rectal temperature were made from 40 normal infants, aged 3-4 months, at home during two days of normal activities. We found that the rectal temperature of a normal, healthy baby may vary from $36.0^{\circ} \mathrm{C}$ at night to $37.8^{\circ} \mathrm{C}$ during active periods of the day. During daytime sleep rectal temperature fell, but to a lesser extent, and for less time than during night time sleeps. Feeds raised the temperature unless the baby slept, when they reduced the rate of fall of temperature. Bottle feeds affected temperature more quickly than breast feeds. The changes in temperature during sleep and after feeds were independent of the room temperature or thermal insulation of clothing and wrapping.
\end{abstract}

During a normal night's sleep, the rectal temperature of 3-4 month old infants changes in a characteristic way, ${ }^{1}$ irrespective of ambient temperature or the thermal insulation of clothing and wrapping within the range normally chosen by parents. ${ }^{2}$ This shows that by this age the adult circadian rhythm of body temperature is beginning to appear, ${ }^{3}$ though the timing of temperature change is not precisely locked to time of day, rather to time of going to sleep.

It may be therefore, that the fall in rectal temperature at night is merely a consequence of sleeping, and not a true circadian rhythm. Babies of this age, however, also sleep during the day, so we can test this hypothesis by monitoring temperature during daytime sleeps, the longest of which can be similar in duration to short night time sleeps. Babies are also fed at bedtime, but not always before day time sleeps, so we may also be able to examine the effects of feeds on the rectal temperature in sleeping and awake babies. In this study therefore we have measured rectal temperature during daytime sleeps, and examined the interactions between the effects of feeding and sleeping on rectal temperature during the day.

University of Leicester, Department of Child Health E S Anderson M P Wailoo

Department of Physiology

S A Petersen

Correspondence to: Dr S A Petersen, Department of Physiology, University of Leicester, PO Box 138 , Leicester LE1 9HN.

Accepted 6 July 1990

\section{Methods}

Forty normal full term babies were recruited at birth, and arrangements made to visit them at home on at least four occasions around 3 months of age. At the first visit basic perinatal data were recorded, together with body weight, head circumference, and skinfold thickness. On each visit three thermistor probes were attached to the baby (a soft rectal probe inserted $5 \mathrm{~cm}$ from the anal margin, and skin probes placed on the forehead and abdomen), and connected to a Grant Squirrell data logger set to record temperatures once a minute. Parents could, if they wished, interrogate the logger, but temperatures were not routinely displayed to them. A fourth probe measured room temperature. We have validated these recording techniques, and shown them to be safe. ${ }^{1}$ Full ethical committee permission was obtained for this study.

Two recording periods were during the day, and two overnight. The data reported here are from the daytime recordings only except that some data from night time sleeps have been included for purposes of comparison. These recordings, of four to seven hours' duration, were chosen to span a normal range of daily activities. Parents were asked to keep a detailed, prospective diary of all the day's events, including feeds, sleeps, nappy changes, periods of activity, etc. In the case of daytime sleeps, parents were asked to check whether the baby was still asleep at 10 minute intervals, so that a reasonably accurate estimate of sleep duration could be obtained, though of course this disturbance may have led some babies to wake a little earlier than normal. At each recording note was made of the number of items of clothing worn by the baby, and the wrappings placed around it for periods of sleep. Tog values were calculated by reference to a table of figures provided by the Shirley Institute, Manchester.

The temperature data were read into a computer, and scrutinised for technical problems, such as loss of probes. Only unblemished data were analysed.

The temperature records were collated with the parental diaries, and periods of recording before and after feeds, or the onset of a sleep identified. In this paper we report on the rectal temperatures. Rectal temperatures were collated at 10 (feeds) or 15 (sleep) minute intervals, and mean and standard errors calculated at each time point. Statistical comparisons were by paired $t$ tests between values at different times for the same individuals, where appropriate, and by unpaired $t$ tests between groups if no pairing was possible.

\section{Results}

Of the 40 subjects studied 22 were boys and 18 girls. The mean (SEM) age at recording was $16.5(0.39)$ weeks. The mean maternal age was $26.95(0.92)$, and the social class distribution resembled that of the general Leicester population. When awake and active the babies were clothed with an average of $4.83(0 \cdot 17)$ tog units of insulation (range $3 \cdot 2-6 \cdot 2$ ), in rooms whose 
temperatures averaged $18 \cdot 11(0 \cdot 40)^{\circ} \mathrm{C}$ (range $10 \cdot 8-21 \cdot 7)$. During sleep they were wrapped with an additional $8.56(0.42)$ tog units of insulation (range 6.9-20.1), in rooms whose ambient temperature averaged $17 \cdot 64(0 \cdot 41)^{\circ} \mathrm{C}$ (range $8 \cdot 7-21 \cdot 3$ ).

To measure the effects of sleep 76 daytime sleeps were recorded, of average duration 87 (17) minutes. Of these 31 were preceded by a feed, and the remainder followed a period $(>1$ hour) of activity, but were not preceded by a feed.

Figure 1 shows rectal temperature during the 31 sleeps which lasted at least 90 minutes. Temperature fell significantly by 45 minutes into the sleep, with a faster rate of fall in babies who were not fed. For both fed and non-fed babies during the day, rectal temperature 45 minutes after bedtime was significantly lower than at bedtime $(\mathrm{p}<0.01$ paired $t$ test with 11 and $18 \mathrm{df}$ respectively): fed babies $37.21(0.05)^{\circ} \mathrm{C}$ at bedtime and $36.82(0.07)^{\circ} \mathrm{C} 45$ minutes later $(n=$ 12). For non-fed babies it was $37.03(0.06)^{\circ} \mathrm{C}$ at bedtime and $36.70(0.04)^{\circ} \mathrm{C} 45$ minutes later.

At 15 and 30 minutes after bedtime, rectal temperature was also significantly lower in nonfed babies than in fed babies: at 15 minutes in fed babies $37.04(0.05)^{\circ} \mathrm{C}$ and in non-fed 36.79 $(0.05)^{\circ} \mathrm{C}$ (p<0.01 unpaired $t$ test with $\left.29 \mathrm{df}\right)$. At 30 minutes in fed babies it was $36.87(0.06)^{\circ} \mathrm{C}$ and in non-fed $36.71(0.04)^{\circ} \mathrm{C}(\mathrm{p}<0.05$ unpaired $t$ test with $29 \mathrm{df}$ ). It rose again before waking. Figure 1 also shows rectal temperature during the first hours of a night's sleep for comparison. The initial rate of fall at night is like that of fed babies during the day, but it continues for longer at night, to stabilise at a significantly lower value. All babies were fed before their night time sleeps. These data were derived from measurements on the subjects from this study, though they are very similar to our previous reports from recordings of another group of babies. $^{1}$

Neither the rate, nor the extent of temperature fall was affected by room temperature or tog value of clothing and wrapping. It was not uncommon for babies well wrapped in warm rooms to cool more quickly, and to a greater extent than those lightly wrapped in cool rooms.

Rectal temperature also falls during short $(<1$ hour) daytime sleeps, though the fall is tran-



Figure 1 The mean (SEM) rectal temperature of 3-4 month old babies during daytime and night time sleeps.

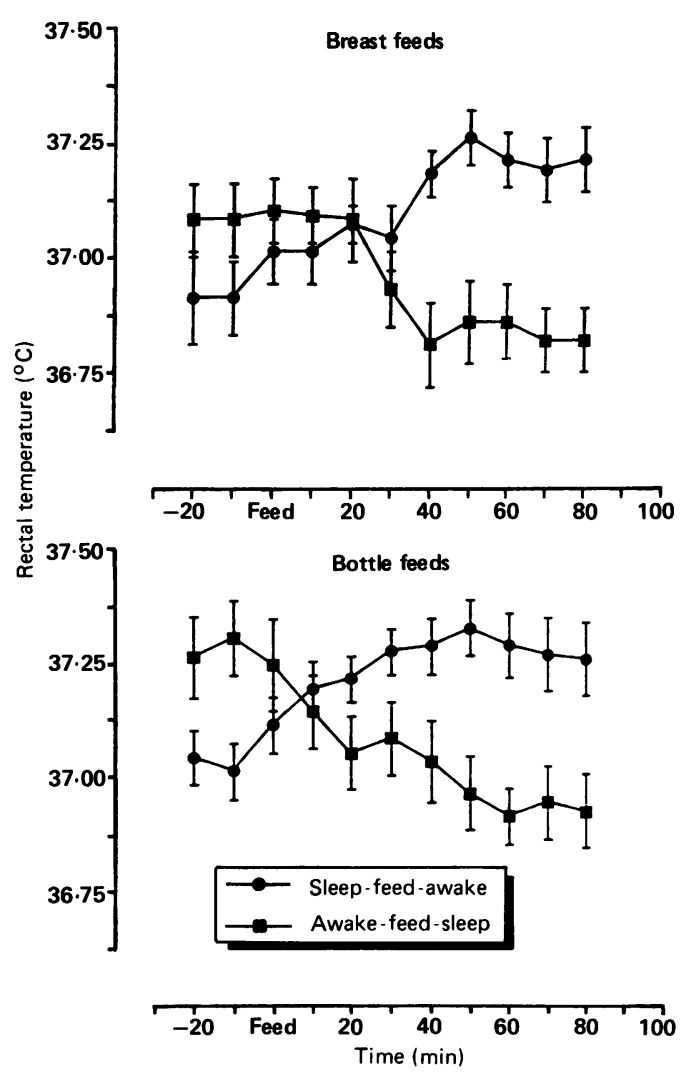

Figure 2 The mean (SEM) rectal temperature of 3-4 month old babies after breast feeds and bottle feeds, followed by either a period of waking or sleep during the day.

sient, as rectal temperature has normally returned to above $37^{\circ} \mathrm{C}$ by the time of waking.

Sixteen of the subjects were wholly breast fed, 22 bottle fed, and two fed at breast and bottle. Most were also given some solids, with bottle fed babies generally given more. Reliable temperature records were obtained before and after 37 bottle feeds and 27 breast feeds. The majority of daytime feeds were followed by a period of waking (27/37 bottle feeds, 15/27 breast feeds), the remainder by sleep within 30 minutes.

Figure 2 shows rectal temperature changes after breast and bottle feeds during the day followed either by sleep or waking. Most feeds followed by waking were preceded by sleep, and vice versa. Rectal temperature 50 minutes after the feed was significantly raised if the baby remained awake, but significantly reduced if it slept: for bottle fed at feed time $37 \cdot 11(0.06)^{\circ} \mathrm{C}$ and 50 minutes later $37.32(0.06)^{\circ} \mathrm{C}, \mathrm{p}<0.05$ by paired $t$ test, $26 \mathrm{df}$; for breast fed at feed time $37.01(0.07)^{\circ} \mathrm{C}$ and 50 minutes later 37.26 $(0.05)^{\circ} \mathrm{C}, \mathrm{p}<0.05$ by paired $t$ test, $14 \mathrm{df}$. For bottle fed babies at feed time who then slept the rectal temperature was $37.24(0.08)^{\circ} \mathrm{C}$ and 50 minutes later $36.96(0.08)^{\circ} \mathrm{C}, \mathrm{p}<0.05$ by paired $t$ test with $9 \mathrm{df}$; for breast fed babies at feed time who then slept $37 \cdot 10(0.07)^{\circ} \mathrm{C}$ and 50 minutes later $36.86(0.09)^{\circ} \mathrm{C}, \mathrm{p}<0.05$ by paired $t$ test, 11 df. The rectal temperature of bottle fed babies rose faster if they stayed awake, and fell more slowly if they slept.

As with changes after sleep we could find no significant effects of room temperature, or tog 
value of clothing and wrapping upon the temperature changes after feeds.

\section{Discussion}

The rectal temperature of a normal 3 month old baby may vary from a minimum of $36.0^{\circ} \mathrm{C}$ during the night to $37 \cdot 8^{\circ} \mathrm{C}$ during active periods of the day. ${ }^{1}$ These variations are not, however, random. Temperature is affected in predictable ways by sleep, feeding, activity, and time of day per se.

Sleep at any time leads to a fall in rectal temperature, but there is an interaction between sleep and time of day. At night temperature falls by $0.8^{\circ} \mathrm{C}$ within two hours of bedtime, and remains low for several hours, even if the baby wakes for a while, ${ }^{4}$ a pattern like that of adults. ${ }^{3}$ During daytime sleeps temperature also falls, often at a faster rate and particularly in babies who have not been fed. The extent of fall is not, however, so great even in sleeps of similar duration. Even when babies sleep for over three hours during the day, their rectal temperature is above $37^{\circ} \mathrm{C}$ well before they wake, whereas babies who wake after three or four hours at night show only a very transient rise in temperature. ${ }^{4}$

During both night and daytime sleeps the rate and extent of temperature fall is independent of both room temperature and thermal insulation of clothing and wrapping within the range chosen by parents, indicating a controlled change, presumably driven by changes in the central 'thermostat'. By 3 months of age, however, this control operates differently during the night and day presumably because of the emergence of circadian rhythms in various physiological systems. ${ }^{3}$
Feeds and activity both tend to raise rectal temperature. It is not uncommon for a recently fed, active baby to have a rectal temperature of $37 \cdot 8^{\circ} \mathrm{C}$. In our studies about $15 \%$ of recently fed, active babies maintain rectal temperature above $37 \cdot 7^{\circ} \mathrm{C}$ for half an hour or more. The effects of feeds are presumably due to the specific dynamic action of the food. This leads to a rise in temperature if the baby is awake, but if asleep, then temperature still falls, albeit more slowly than if the baby has not been fed.

The effects of bottle feeds on temperature appear much more quickly than those of breast feeds. It is possible that the temperature of bottle milk is higher than the babies body temperature, so that it provides some direct heating, but it is also likely that the bottle fed babies take more milk more quickly. The bottle fed babies were also much more likely to be given some solid food, such as rusk or baby rice.

It is clear, however, that a temperature that may be perfectly normal under some conditions can be quite abnormal under others, and if a spot reading of deep body temperature in a baby is to be correctly interpreted, then the time of day, sleep state, and feeding history must be known.

1 Wailoo MP, Petersen SA, Whittaker H, Goodenough P. Sleeping body temperatures in 3-4 month old infants. Arch Dis Child 1989;64:596-9.

2 Wailoo MP, Petersen SA, Whittaker H, Goodenough P. The thermal environment in which $3-4$ month old infants sleep at home. Arch Dis Child 1989;64:600-4.

3 Minors DS, Waterhouse JM. (1981) Circadian rhythms and the human. Bristol: John Wright, 1981.

4 Wailoo MP, Petersen SA, Whittaker H. Disturbed nights in 3-4 month old infants - the effects of feeding and thermal environment. Arch Dis Child 1990;65:499-501. 